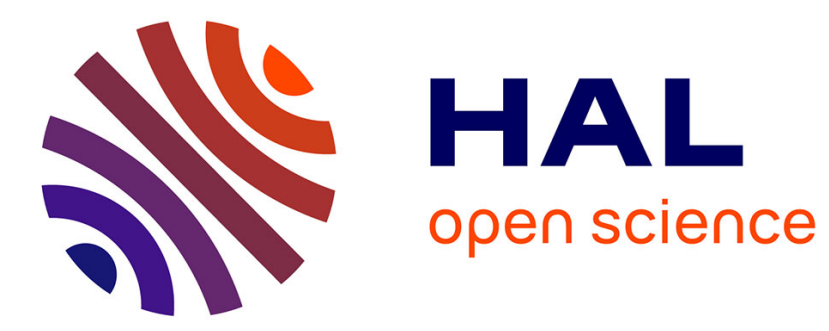

\title{
Interfacial behaviour of polyaniline as an organic electronic material
}

Chee Heng Teo, Nireeksha S. Karode, Kamran Abid, Faiz Rahman

\section{To cite this version:}

Chee Heng Teo, Nireeksha S. Karode, Kamran Abid, Faiz Rahman. Interfacial behaviour of polyaniline as an organic electronic material. Journal of Physics and Chemistry of Solids, 2011, 10.1016/j.jpcs.2011.04.010 . hal-00757444

\section{HAL Id: hal-00757444 \\ https://hal.science/hal-00757444}

Submitted on 27 Nov 2012

HAL is a multi-disciplinary open access archive for the deposit and dissemination of scientific research documents, whether they are published or not. The documents may come from teaching and research institutions in France or abroad, or from public or private research centers.
L'archive ouverte pluridisciplinaire HAL, est destinée au dépôt et à la diffusion de documents scientifiques de niveau recherche, publiés ou non, émanant des établissements d'enseignement et de recherche français ou étrangers, des laboratoires publics ou privés. 


\section{Author's Accepted Manuscript}

Interfacial behaviour of polyaniline as an organic electronic material

Chee Heng Teo, Nireeksha S. Karode, Kamran Abid, Faiz Rahman

PII:

S0022-3697(11)00109-0

DOI: doi:10.1016/j.jpcs.2011.04.010

Reference: PCS 6449

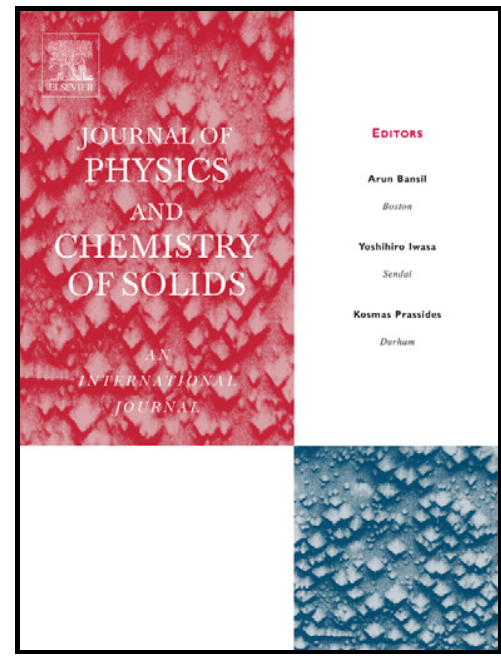

www.elsevier.com/locate/jpcs

To appear in: $\quad$ Journal of Physics and Chemistry of Solids

Received date: $\quad 20$ August 2010

Revised date: $\quad 17$ January 2011

Accepted date: 18 April 2011

Cite this article as: Chee Heng Teo, Nireeksha S. Karode, Kamran Abid and Faiz Rahman, Interfacial behaviour of polyaniline as an organic electronic material, Journal of Physics and Chemistry of Solids, doi:10.1016/j.jpcs.2011.04.010

This is a PDF file of an unedited manuscript that has been accepted for publication. As a service to our customers we are providing this early version of the manuscript. The manuscript will undergo copyediting, typesetting, and review of the resulting galley proof before it is published in its final citable form. Please note that during the production process errors may be discovered which could affect the content, and all legal disclaimers that apply to the journal pertain. 


\title{
Interfacial Behaviour of Polyaniline as an Organic Electronic Material
}

\author{
Chee Heng Teo, Nireeksha S. Karode, Kamran Abid and Faiz Rahman \\ Department of Electronic and Electrical Engineering \\ University of Glasgow \\ Rankine Building, Oakfield Avenue \\ Glasgow G12 8LT \\ Scotland, United Kingdom
}

\begin{abstract}
This paper reports on investigations carried out to study the behaviour of contacts between polyaniline and surface electron rich solids. The objective of the study was to study polymer-conducting system hybrids. Experiments were carried out on three metals, graphite sheets and on indium arsenide. The results show that in the case of metals, where there is good alignment of the metal's Fermi level with the LUMO bands of the polymer one gets a lower contact resistance. With graphite a good, low resistance, ohmic contact was obtained whereas with indium arsenide a non-linear I-V characteristic was observed. Behaviour of a polyaniline-silica-silicon structure is also described where gate-controlled conductivity enhancement was observed.
\end{abstract}


Corresponding Author: Faiz Rahman

Telephone Number: +44 1413302091

Fax Number: +44 1413304907.

E-mail Address: f.rahman@elec.gla.ac.uk

Keywords: conducting polymers (A); interfaces (A); conjugated system (A); compound semiconductor (A); gate control (C) 


\section{Introduction}

Polymer-based organic electronics is making rapid strides these days with applications in both electronics and optoelectronics attracting the attention of researchers worldwide [1,2]. Continued progress in this field requires advances in a number of disciplines such as the physics and chemistry of conducting polymers, fabrication technologies suitable for polymeric materials, novel device architectures and implementation of material and device modelling $[3,4]$. The first among these is of particular importance as better fundamental understanding of organic conducting materials is likely to be the key to better devices and integrated systems of the future. Understanding the long term ageing behaviour of conducting polymers and their interactions with the surfaces of other materials is widely accepted as the key to producing low-cost commercial polymer electronics devices. The understanding of electrical conduction in conjugated polymers has advanced rapidly over the past few years but much is still unknown. The interfaces formed by conjugated polymers with various other conducting materials are potentially of great significance because their behaviour affects many kinds of devices. Advances in metal-semiconductor contact technology has improved conventional inorganic semiconductor devices and similar advances in organic contact technology is certain to benefit organic electronic and optoelectronic devices. Here, we report our work on polyaniline's interfaces with a number of surface electron-rich solids. The combinations reported are particularly interesting because here polyaniline - a p-type organic conductor is combined with metallic and other strongly n-type materials. The way in which charge is carried across such interfaces is of great importance for both active and passive polymer electronic devices. 
Polyaniline (PANI), used in our work, is a well-known conducting polymer that is used for a variety of applications ranging from anti-static packaging to electromagnetic shielding. Various forms of polyaniline could be synthesised and these have somewhat different properties. The electronic and optoelectronic properties of polyaniline have been extensively investigated $[5,6]$. Commercially, polyaniline is available as a solution in various solvents such as toluene, xylene, tetrahydrofuran and water. Films could be spray, dip or spin coated from any of these products. In the past, polyaniline films have been used in resistive sensors because of their ability to undergo rapid change in electrical conductivity on doping with certain chemical

species [7-12]. The polyaniline we used in this work was obtained from Panipol in Finland (Panipol-T) and consisted of a $6.7 \%(\mathrm{w} / \mathrm{w})$ solution of polyaniline in toluene. It should be mentioned here that we tried both water- and toluene-based solutions of polyaniline and found that water-based polyaniline produced inferior thin-films as compared to toluene-based polyaniline. For this reason it was decided to use PanipolT instead of Panipol-W - the water-based polyaniline also available from Panipol.

\section{Polyaniline-metal contacts}

Contacts between conducting polymers and metals are of obvious interest because of their use in organic electronic devices [13]. A good review on this topic has been published by Mark Lonergan [14]. Optoelectronic devices, such as OLEDs, require at least one contact to be transparent and indium tin oxide (ITO) is usually used for this purpose. Aluminium-doped zinc oxide (AZO) is also being considered for this application. The other contact can be an opaque metal contact and it also usually acts 
as a light reflector in optoelectronic devices. Various metals can form good ohmic contacts with a number of electrically conducting conjugated polymers. It is chiefly the line-up of the metal's Fermi level with the position of the lowest unoccupied molecular orbital (LUMO) level in the polymer that determines the electrical character of the polymer-metal contact. Given the p-type conduction characteristic of conjugated polymers, high work function metals, such as gold, can form low contact resistance ohmic contacts. Because polymers are not amenable to many processing techniques that are routinely used with inorganic semiconductors so metallic contacts to polymers are often deposited by the use of a shadow mask. This consists of a metal plate with holes in it. We used a $2 \mathrm{~mm}$ thick aluminium shadow mask with $1.5 \mathrm{~mm}$ diameter holes in it for the work that is reported here.

Our work on metal-polymer contacts was carried out only to obtain comparative data with which contacts to other, more interesting, electron rich solids could be compared. For this purpose, three metals were chosen for deposition on 150 nm thick PANI films spin-coated on glass substrates. These metals were gold, nickel and aluminium. Their work functions are $5.2 \mathrm{eV}, 5.1 \mathrm{eV}$ and $4.1 \mathrm{eV}$, respectively (all these values are approximate to within 5\%). As the work functions of all metals are sensitive to surface conditions so our aim was to investigate if annealing PANI-metal contacts could produce long term stable values of resistances. For this purpose, we carried out measurements on contact pairs where each metal contact, whether gold, nickel or aluminium, was a $1.5 \mathrm{~mm}$ diameter circle separated from a neighbouring contact by a distance of $1 \mathrm{~cm}$ (centre-to-centre), as shown in the inset to Fig. 1. Resistances were measured by a Fluke bench top multimeter, at room temperature. These measurements were taken both immediately after contact deposition and after 
an annealing step where samples were kept in a heated furnace tube at $80{ }^{\circ} \mathrm{C}$ for 12 hours under flowing nitrogen gas. The temperature was intentionally kept much lower than the reported glass transition temperature $\mathrm{T}_{\mathrm{G}}$ of polyaniline (around $220-250{ }^{\circ} \mathrm{C}$, depending on the degree of polymer cross-linking) [15] but high enough that the polymer was allowed to relax thermally. Furthermore, $80{ }^{\circ} \mathrm{C}$ was found to be high enough to get rid of any trapped toluene, as indicated by a stable film thickness. The results are summarised in Fig. 1. Here, small circles show resistances before annealing and large circles show resistances after annealing for the three metals with work functions stated above. There was very little difference in resistances measured after contact annealing when compared to resistances measured immediately after contact deposition, showing the absence of physical or chemical reactions at metalpolyaniline interfaces, at least for the three metals that were investigated in this work. In addition, we also simulated contact ageing by heating them in flowing oxygen gas at $80{ }^{\circ} \mathrm{C}$ for 48 hours. The resistances obtained after that treatment appear in Fig. 1 as horizontal bars, for the three cases. Aluminium and nickel contacts showed an increase in resistance but curiously we found reduced resistance in the case of goldpolyaniline contacts. As gold is a noble metal that doesn't react with oxygen easily so a possible explanation may be based on oxidative doping of polyaniline causing enhanced conductivity. It should be mentioned here that we also examined the behaviour of copper contacts to polyaniline and found their behaviour similar to that of gold in forming low resistance contacts. However, copper is not a recommended contact material because it oxidizes easily and the contacts increase in resistance quite rapidly. 


\section{Polyaniline-graphite contacts}

Graphite is a particularly interesting material to combine with conducting polymers because it is a fully conjugated macromolecule and is thus structurally and electronically compatible with conducting polymers. This was our motivation for investigating graphite-polymer contacts. Graphite consists of a layer lattice with planes of hexagonal carbon atoms, each bonded to three of its neighbours in the plane with $\mathrm{sp}^{2}$ hybridised bonds. The atoms in a plane are separated by $1.42 \AA$ from each other and the planes themselves are separated from each other by the larger distance of $3.35 \AA$ [16]. In contrast to the strong covalent bonds connecting the in-plane carbon atoms, individual planes in graphite are connected to their immediate neighbours above and below by weak van der Waals forces, allowing planes to shear and slide easily past each other, giving graphite its soft, lubricating character. This structure also endows graphite with rather special electronic properties. The $\mathrm{sp}^{2}$ in-plane hybridisation leaves a sheet of almost free electrons immediately above and below each plane of carbon atoms. These sheets can carry electric currents easily, giving graphite its anisotropic electrical (and thermal) conduction properties [17,18]. Each hexagon in the graphite layer planes resembles a benzene ring in possessing alternating single and double bonds and the structure is similarly stabilised by resonance. The conjugated aromatic character of in-plane bonding is similar to that found in more complicated conjugated aromatic conducting polymers such as polyaniline. In a sense, a graphite plane is the simplest possible conjugated aromatic conductor. Recognising this fact, we studied a bilayer of thin spin-cast PANI on a flat polycrystalline graphite substrate. We should note here that previous reported studies 
have described the electrical properties of graphite composites with various conducting and non-conducting polymers [19] whereas our study was focused on planar contacts with a view to their future application in polymer electronics. Our graphite was obtained as a thick carbon foil (99.95\% purity, rigid graphite, fine grain) from Goodfellow in Cambridge U.K. A 1 square $\mathrm{cm}$ piece of this graphite sheet, 250 microns thick, was cleaned with solvents, dried and baked in an oven at $110{ }^{\circ} \mathrm{C}$ for 3 hours. A small square of silica was then sputtered in the centre of this sample using a DC magnetron sputtering system. This deposition system operated with argon gas at a background pressure of $2.3 \times 10^{-4}$ Torr. The silica square had dimensions of $6 \mathrm{~mm} \times 6$ $\mathrm{mm}$ and the rest of the sample was protected by a shadow mask. The silica island served as a barrier to prevent the subsequent polymer layer from subsiding inside the porous structure of graphite. PANI in toluene was spun on it at 3000 RPM for 30 seconds. A circular $1.5 \mathrm{~mm}$ diameter gold contact was evaporated on the PANI film on top of the polymer lying on the silica island. Another contact to bare graphite was made with silver paint close to one edge of the sample. A schematic diagram of the sample structure is shown in Fig. 2. In this device current flowed from the gold contact to the PANI layer down to graphite and then out through the silver contact. A room temperature I-V curve of this device is seen in Fig. 3. This and other such measurements reported here were taken by an Agilent model 4155B Semiconductor Parameter Analyser (SPA) equipped with a wafer contact probe station. As seen from the plot, the current-voltage characteristic is straight with overall device resistance of 10.3 $\Omega$. This includes the bulk resistances of PANI and graphite as well as the two contact resistances. Although graphite's surface is electron rich while PANI has holedominated charge transport, this system shows no evidence of charge conversion at the graphite-PANI interface. This would suggest that the common conjugated 
character of the constituents is important and charge transport encounters no appreciable resistance in crossing this kind of interface. The general conjugated polymer-graphite interface system is potentially important for polymer electronics. Partly this importance arises from the use of single graphitic sheets - graphene - in future organic electronic devices and partly from the rich diversity of conjugated polymer-graphite interfaces that are possible. Thus one can use not only a variety of conducting polymers but also an unlimited number of intercalated graphitic systems to build such interfaces.

\section{Polyaniline-InAs contacts}

Indium arsenide (InAs) has the unique property among common semiconductor materials to have its Fermi level pinned inside the conduction band at the surface. On moving inside an InAs sample from the surface, the Fermi level relaxes and moves to its position half way between the edges of the conduction and valence bands. Thus, a natural inversion layer of free surface electrons exists at InAs free surfaces. The bulk of the material, however, behaves as any other narrow band gap compound semiconductor with a room temperature band gap of $0.36 \mathrm{eV}$. The band bending at the surface thus causes a 2D electron gas (2DEG) layer to exist on InAs surfaces, making them behave as a metal. These electrons have a high mobility of around 33,000 $\mathrm{cm}^{2} / \mathrm{Vsec}$ and a low effective mass of just 0.025 times the mass of a free electron $(9.1$ x $10^{-31} \mathrm{~kg}$ ). The metallic character of InAs surface has been recognised for a long time and has even been used for making hybrid superconductor-semiconductor devices that reveal much information about the interaction of superconductivity with normal electron systems [20-23]. In this work we constructed a similar hybrid device using 
polyaniline as one component of the hybrid. An InAs-PANI hybrid is potentially interesting because whereas the InAs surface is of a metallic electron-rich character, PANI has majority hole-dominated electrical transport. Our InAs-PANI device was made in a way that was very similar to that described in the previous section on the graphite-PANI device except for the presence of the silica island which was not needed here because InAs doesn't have a porous surface. Similar to the graphitePANI device, here too we had a gold electrode on top of the PANI film and a silver electrode on bare InAs. Room temperature I-V characteristics for this device are shown in Fig. 4. The plots are quite non-linear due to the charge conversion process that goes on at the interface. Electrical conduction changes from electron-dominated to hole-dominated character and vice-versa at the interface and this gives rise to a contact potential which shows up as the non-linearity in the current-voltage characteristics. The contact potential could be estimated as about 0.77 volt from these measurements. The large contact potential is typical of a charge conversion interface. Of the two plots shown in the figure, the upper curve is for an as-spun PANI film on InAs whereas the lower curve was obtained when the device was exposed to gaseous ammonia. Ammonia is well-known to interact strongly with PANI, changing the polymer's colour from deep green to deep blue and markedly increasing the resistivity. The emeraldine base form of polyaniline when treated with acids such as $\mathrm{HCl}$ gets converted into a highly electrically conductive emeraldine salt form. This form of polyaniline is thought to form by the protonation of the base form rather than by the oxidation of the p-electron system as happens with other conducting polymers [24]. On exposing the conducting form of polyaniline to ammonia the bridging nitrogen atoms between the aromatic rings undergo de-protonation. This forms ammonium ions, $\mathrm{NH}_{4}^{+}$. These, in turn, may combine with counter dopants, that are 
present from the polyaniline polymerisation process, to form ammonium salts. Loss of protons causes the observed fall in conductivity and the change in film colour. This hypothesis though widely accepted may not be entirely correct as the stability of ammonium salts would cause the effect to be almost completely irreversible [25]. In reality, as gas is allowed to diffuse out of the polymer film, the polyaniline film rapidly reverts back to its conducting form; changing its colour from dark blue back to green. This would imply that ammonium ions are not bound by anions in the polymer matrix and that the protons are either weakly held by ammonia molecules or are somehow only rendered electrically inactive. Ammonium ions themselves have no effect on this process and can not inter-convert between the two forms of polyaniline. The increase in resistivity causes the I-V curve to shift downwards. The non-linearity of these curves as well as the resistance difference between pure and ammoniaadsorbed PANI films are seen more clearly in the dynamic resistance plots derived from the I-V characteristics and shown in Fig. 5 here. This figure shows scatter plots of $\Delta \mathrm{V} / \Delta \mathrm{I}$ at different bias voltage values for both plots shown in Fig. 4 . The lines shown with the scatter plots are trend lines. It is clear that with increasing bias voltage the device resistance falls steadily. The zero bias resistance without and with ammonia in the PANI film were $26.3 \Omega$ and $31 \Omega$ respectively. We should note here that a conjugated polymer-compound semiconductor diode based on polypyrrole-InP interface was described several years ago by Mark Lonergan [26] but as InP is not a surface electron rich semiconductor so the results described in that work are very different from our recent findings described here. 


\section{Polyaniline-silica-silicon structures}

Metal-insulator-semiconductor (MIS) structures are the defining feature of all insulated-gate field-effect transistors. Various metal and insulator combinations have been used with a variety of semiconductor materials. Some combinations display transistor behaviour and are useful for making metal oxide semiconductor field-effect transistors (MOSFETs). Other combinations show change in electrical conductivity as a result of gate biasing but no transistor action [27]. In order to investigate the behaviour of polyaniline in such a structure we fabricated polyaniline-silica-silicon structures. This was done by first oxidising n-type doped silicon in dry oxygen to create a high-quality thermally-grown silica layer $\sim 90 \mathrm{~nm}$ thick. Polyaniline was then spin-coated at 3000 RPM on this substrate. Gold dots, $2 \mathrm{~mm}$ in diameter, were deposited on top of polyaniline film through a shadow mask. The sample was then attached to a copper back-plane using silver paste so that the silicon substrate was in electrical contact with copper. In this configuration, the silicon substrate and, by extension, the copper plane acted as a gate. The current flow between goldpolyaniline contacts was measured at different applied voltages between the contacts as a voltage applied on the copper plate (with respect to one of the gold contacts) was varied. As seen in Fig. 6, clear gate-mediated conductivity variation was observed with the current increasing almost linearly as the applied gate voltage was increased to -20 volts. From this plot, a transconductance value of $0.523 \mathrm{~mA} /$ volt can be obtained. This observation, which we believe is being reported for the first time, opens up the possibility of using field-induced conductivity variation in such applications as modulating the intensity of OLEDs where polyaniline is used as a hole injection layer [28] and in controlling the sensitivity of polyaniline-based sensors. 


\section{Conclusions}

We have described work on polyaniline film's interfaces with metals, graphite and indium arsenide - all solids rich in surface electrons. With metals we found contact resistances dependent on metal work function with little change brought about by post deposition annealing. Graphite-PANI interface showed no charge conversion at the interface and graphite appears to form very good ohmic contact with PANI films. This suggests that contacts made of metals deposited on graphite sputtered on conjugated polymers similar to polyaniline could be ideal for organic electronic devices; even better than the gold-polymer contacts that are widely used at this time. Charge conversion was observed at InAs-PANI interface with an interface contact potential of 0.77 volt. This observation has potential for use in high non-linearity hybrid InAsPANI devices.

\section{Acknowledgements}

The authors would like to acknowledge technical help received from Thomas O'Reilly and Donald Nicolson in this work. 


\section{References}

[1] G. Horowitz, Adv. Mater. (Weinheim, Ger.) 10 (1998) 365-377.

[2] K. Cousins, Polymers in Electronics; Rapra Technology Ltd. 2006, ISBN: 1847350062.

[3] R. Farchioni and G. Grosso (Editors), Organic Electronic Materials: Conjugated Polymers and Low Molecular Weight Organic Solids (Springer Series in Materials Science), Springer 2001.

[4] F. Rahman, N. P. Johnson and T. J. Slight, J. Appl. Phys. 98 (2005) 124504124508.

[5] R. P. McCall, J. M. Ginder, J. M. Leng, J. H. Ye, S. K. Manohar, J. G. Masters, G. E. Asturias, A. G. MacDiarmid and A. J. Epstein, Phys. Rev. B 41 (1990) 5202-5213.

[6] T. Berzina, V. Erokhin, M. P. Fontana, J. Appl. Phys. 101 (2007) 024501-024506.

[7] J. M. G. Laranjeira, H. J. Khoury, W. M. Azevedo, E. A. Vasconcelos and E. F. Silva, Brazilian Journal of Physics 32 (2003) 421-423.

[8] G. Ballun, F. Hadju and G. Harsanyi, 26th International Spring Seminar on Electronics Technology: Integrated Management of Electronic Materials Production (2003) 471-475. 
[9] L. Dai, P. Soundarrajan and T. Kim, Pur. Appl. Chem. 74 (2002) 1753-1772.

[10] A. Boyle, E. M. Genis and M. Lapkowski, Synth. Met. 28 (1989) 769-774.

[11] C. Conn, S. Sestak, A. T. Baker and J. Unsworth, Electroanalysis 10 (1998) 1137-1141.

[12] E. W. Paul, A. J. Ricco, M. S. Wrighton and Y. Nishioka, J. Phys. Chem. 89 (1985) 1441-1447.

[13] R. Lazzaroni, M. Lögdlund, A Calderone, J. L. Dannetun, C. Fauquet, C. Fredriksson, S. Stafström and W. R. Salaneck, Synthetic Metals 71 (1995) 2159-2162.

[14] M. Lonergan, Annu. Rev. Phys. Chem. 55 (2004) 257-298 .

[15] R. Emirkhanian, M. Salvia, J. Ferreira, N. Jaffrezic, L. Chazeau and A. Mazzoldi, Materials Science and Engineering: C 26 (2006) 227-231.

[16] M. Inagaki (Editor), New Carbons - Control of Structure and Functions, Elsevier Science, 2000.

[17] T. Enoki, M. Suzuki and M. Endo (Editors), Graphite Intercalation Compounds and Applications, Oxford University Press, New York, 2003. 
[18] F. Rahman, Appl. Phys. A 86 (2007) 221-224.

[19] I. A. Tchmutin, A. T. Ponomarenko, E. P. Krinichnaya, G. I. Kozub and O. N. Efimov, Carbon 41 (2003) 1391-1395.

[20] F. Rahman, T. J. Thornton, R. Huber R, L. F. Cohen, W. T. Yuen and R. A. Stradling, Phys. Rev. B 54 (1996) 14026-14031.

[21] R. Huber, F. Rahman, T. J. Thornton, A. Norman, R. A. Stradling, J. Vac. Sci. Tech. $B 16$ (1998) 1244-1248.

[22] F. Rahman and T. J. Thornton, Superlattices and Microstructures 25 (1999) $767-$ 774.

[23] F. Rahman, T. J. Thornton, Appl. Phys. Lett. 77 (2000) 432-434 .

[24] W. Huang, B. D. Humphrey and A. G. MacDiarmid, J. Chem. Soc. Faraday Trans. 82 (1986) 2385-2400.

[25] S. A. Krutoverstsev, S. I. Sorokin, A. V. Zorin, Y. A. Letuchy and O. Y. Antonova, Sensors and Actuators B 7 (1992) 492-494 .

[26] M. C. Lonergan, Science 278 (1997) 2103-2106. 
[27] F. Rahman, B. L. Gallagher, M. Behest and J. de Boeck, Appl. Phys. Lett. 73 (1998) 88-90.

[28] Habiba Bejbouj, Laurence Vignau, Jean Louis Miane, Thomas Olinga, Guillaume Wantz, Azzedine Mouhsen, El Moustafa Oualim and Mouhammed Harmouchi, Materials Science and Engineering: B 166 (2010) 185-189. 


\section{Figure captions}

Fig. 1. Contact resistance of annealed and non-annealed PANI-metal contacts. Small circles show contact resistance before annealing whereas large circles show contact resistance after annealing. Horizontal bars indicate resistance obtained after leaving the metals exposed to air for two days. The inset shows contact geometry where 1.5 $\mathrm{mm}$ diameter contacts were separated by a distance of $10 \mathrm{~mm}$.

Fig. 2. Schematic diagram showing the structure of PANI-over-Graphite device.

Fig. 3. Current-voltage characteristic of PANI-graphite contact.

Fig. 4. Current-voltage characteristic of PAN-InAs contact.

Fig. 5. Dynamic resistance of PANI-InAs contact.

Fig. 6. Variation of the contact-to-contact current in polyaniline as a function of applied gate voltage. 
Fig 1

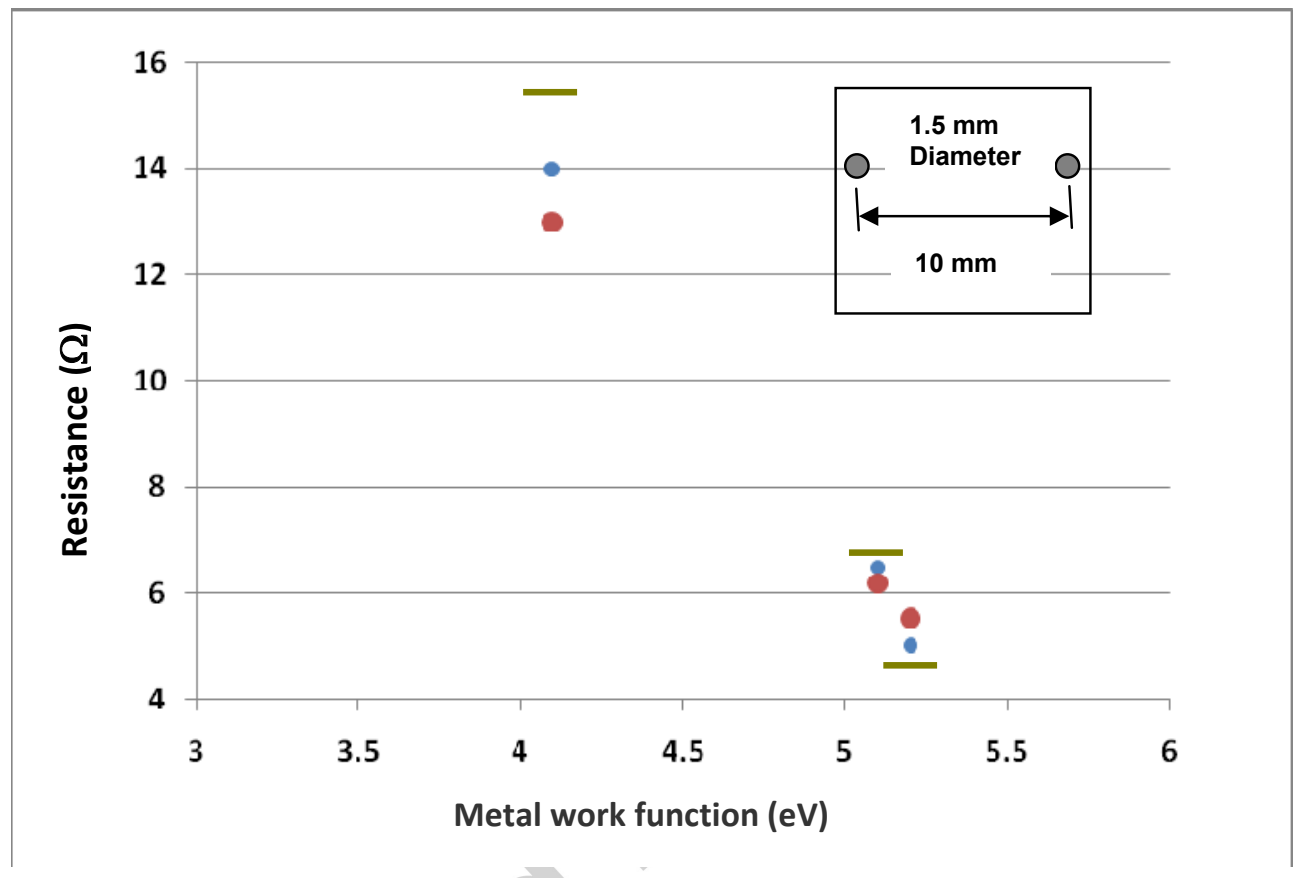


Fig 2

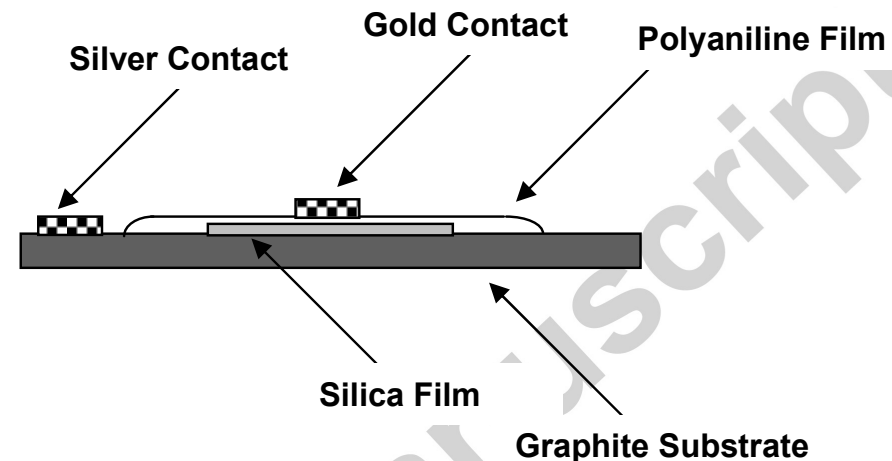


Fig 3

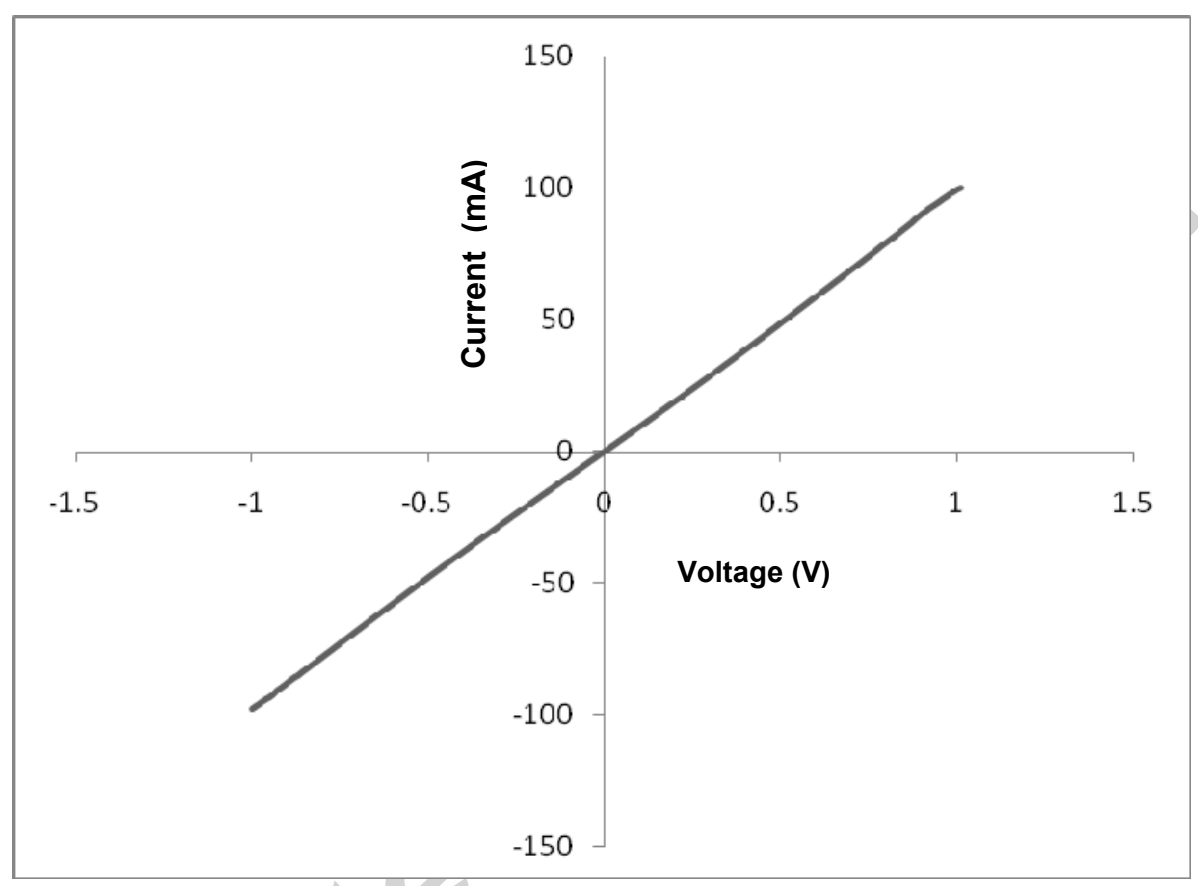


Fig 4

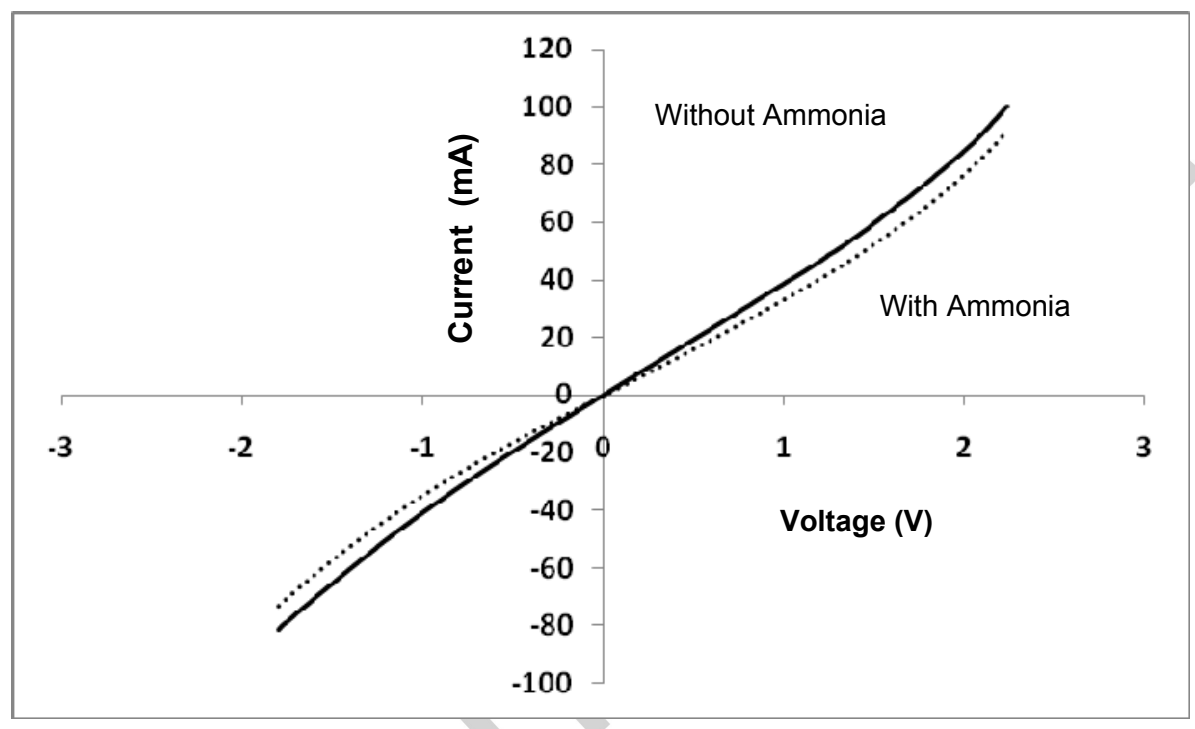


Fig 5

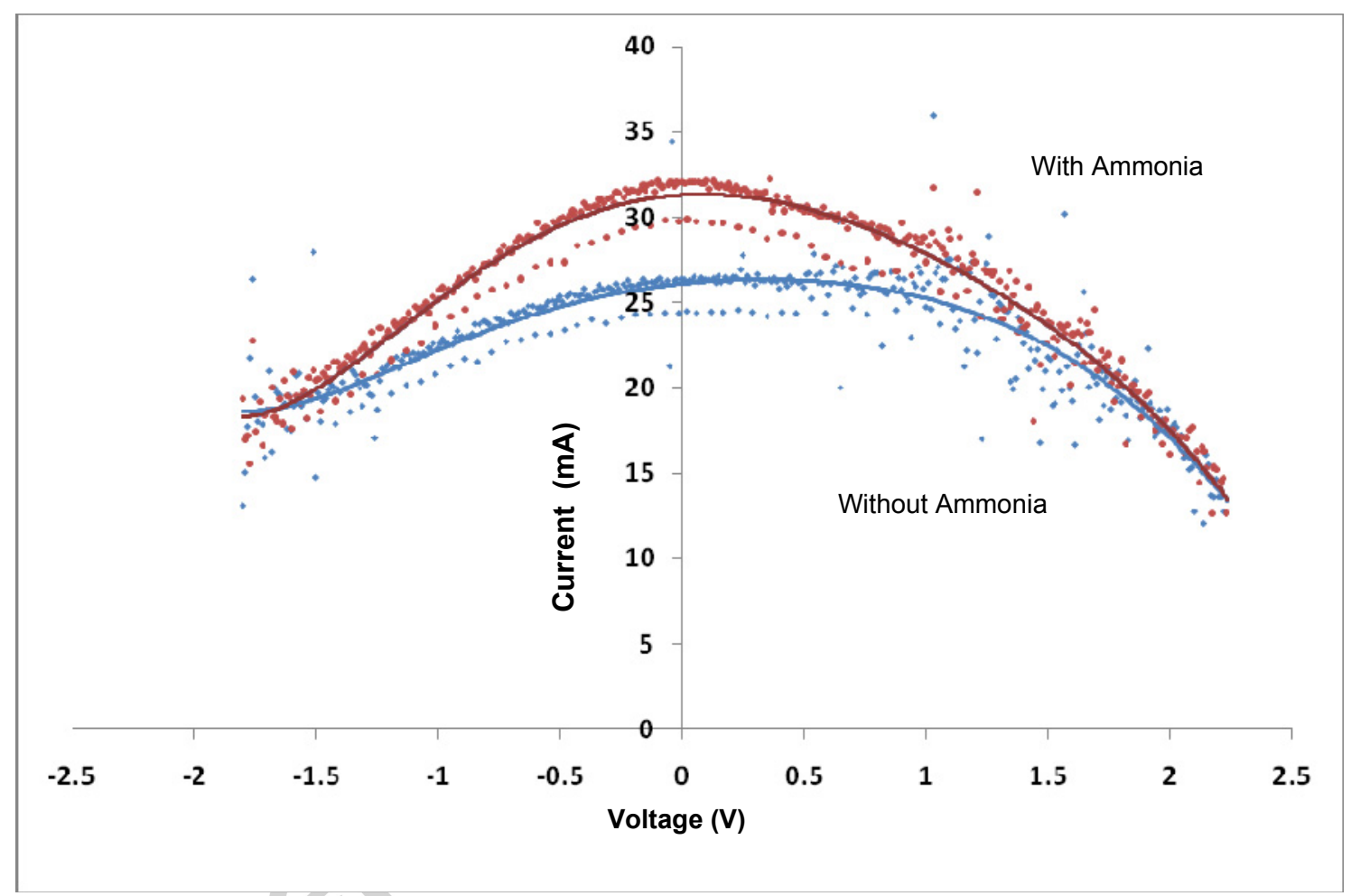


Fig 6

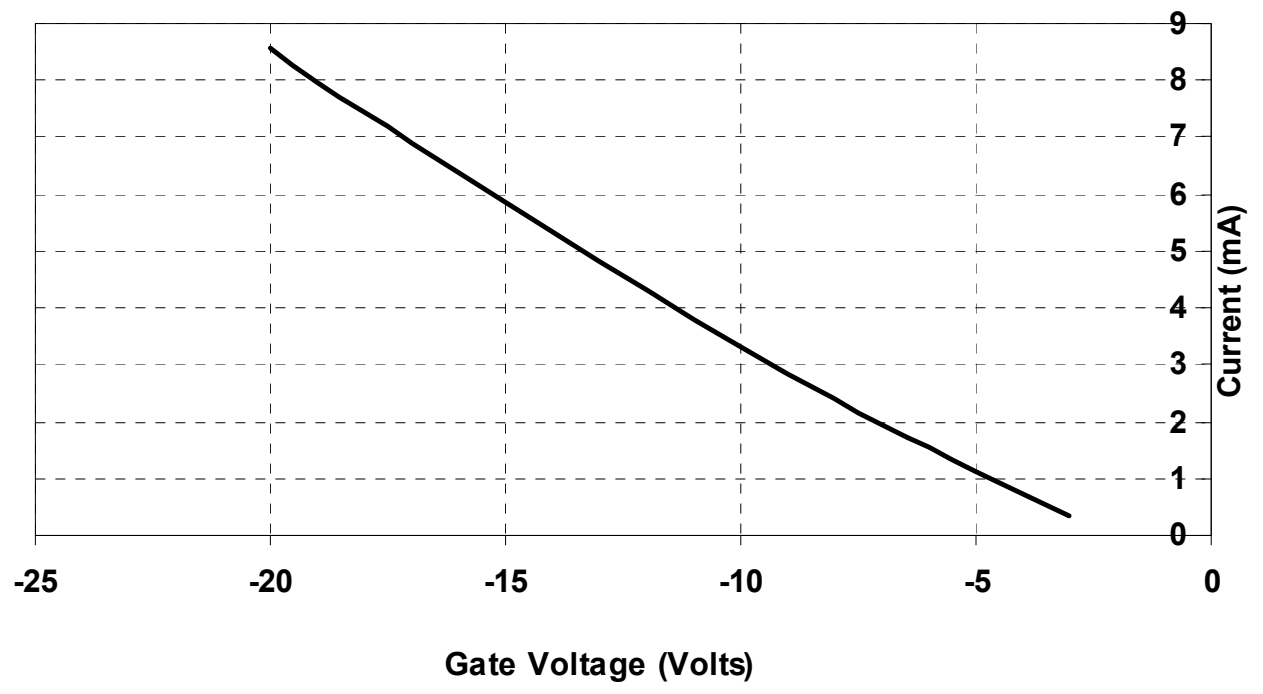




\section{Research Highlights}

In this work we explore interfaces of conducting solids with polyaniline

We describe the preparation of hybrids containing polyaniline films

We also describe the field effect in polyaniline 